\title{
The Language of Health Reform and Health Management: critical issues in the management of health systems
}

\author{
DS Briggs and G Isouard
}

\begin{abstract}
Health reform has been a constant feature of most health systems for a number of decades and has often focused on structural change. The lexicon of health reform and health management has also become intertwined with managers reporting that reform has become a constant and that rather than influencing that change they are in fact influenced by it and by its impact on their role, professional development and career.
\end{abstract}

There is a challenge for health service managers to return to a leadership role in enabling health reform. In doing so will this challenge us to think differently about management?

This article addresses the significant body of research into health reform and health management through the lens of language used in reporting the context and the significant impact that it has had on the management role. It describes what directions that role might take, the qualities required in selecting capable managers and questions the current status quo in the education, training and development of this significant sector of the health system workforce.
It concludes by proposing a way forward that acknowledges that contemporary health reform is shifting the paradigm of healthcare delivery in a way that requires the dominant view of health management to be challenged. This might be achieved by the use of a critical lens on the language of management, a focus on a grounded approach about what managers need to do and an acceptance of variability in that role in adaptive complex contexts.

Abbreviations: DNOP - Distributed Networks of Practice; MDG - Millennium Development Goals; PHC - Primary Healthcare; PHN - Primary Health Network; SDG - Sustainable Development Goals; SEDOH - Social Economic Determinants of Health; SHAPE - Society for Health Administration Programs in Education.

Key words: health reform; health management role; lens; language; critical inquiry.

\section{David Briggs}

Professor Health Systems Management

Naresuan University Thailand

Adjunct Associate Professor

University of New England

New South Wales, Australia

\section{Godfrey Isouard}

Associate Professor

University of New England

New South Wales, Australia

Correspondence:

dsbriggs007@gmail.com

\section{Introduction}

Critical management inquiry questions the 'alignment of knowledge, truth, and efficiency' within 'notions of power, control, and inequality'. [1] These critical perspectives contrast with the normative, rational view of management and are important in seeking to present the personal perspective of managers about their role, possibly in contrast to that normally presented in the literature.

Health reform has been a constant feature of most health systems for a number of decades and has often focused on structural change. The lexicon of health reform and health management has also become intertwined with managers reporting that reform has become a constant and that rather than influencing that change they are in fact influenced by 
it and by its impact on their role, professional development and career. [2] Managers are said to be 'equipped with a range of languages that describe their context and their challenges'. [2, p.642] These languages represent theory, but do not completely describe the context or role and it has been said that 'They are partial stories... overlapping unknowably and are said to be incommensurable'. [3, p.12] Hence this article responds to the challenge by Professor Judith Dwyer in her 'Chris Selby Oration' at the 2016 SHAPE Symposium, Melbourne for health managers to take the leadership role in national health reform. This response takes the form of examining the lexicon of health reform and health management language described in contemporary research and that is illustrated within the articles in this special edition.

\section{Reform}

Although evidence shows that health reform fails to realise its intended efficiencies, governments hold high expectations of it. [2,4] The agenda is often driven by strong language that results in better outcomes in healthcare. In Australia, the Commonwealth and States have historically been deficient in the required capacity and capability to fulfil the rhetoric to drive and lead the major process of reform. However, such deficiency of skill and capacity is not just isolated to the domains of government, but clearly found at the coalface amongst health managers who are positioned to provide leadership within the reformed organisational environment. $[5,6]$ There is an underlying lexicon that is often spruiked that restructuring is the precursor to systems improvement which then leads to better health. However, research has shown that 'big bang' changes, often supplemented with raised expenditure, are used by governments to send a strong message that the community will gain though improved health status. Boxall and Buckmaster reported that the likelihood of success in implementing such 'big bang' reform is small. [7] Experience has shown that success is more likely to be achieved through a much smaller scale incremental strategic approach.

The move to the aggregation of health services into health systems reflects the effect of political and economic change, a move from centrally planned economies to that of markets with reduced state intervention and control and greater decentralisation and the increased adoption of commercial business practices focused on process. [8] This suggests that the emphasis and, therefore the practice of health management will mostly be about managing systems of healthcare and models of healthcare delivery that will span organisational boundaries. So this change, well in transition in some nation states and lagging in others, suggests perhaps different skills and roles for health managers. A seminal influence on how the policy of health reform is currently enacted and how healthcare is delivered and practised are the similar concepts of the 'principle of subsidiarity' and that of 'localism'. The principle of subsidiarity, also mentioned by Podger in this issue suggests that 'government should only fulfil a subsidiary function for those tasks that cannot adequately be dealt with by lower tiers'. [10, p.11] Subsidiarity context is meant to lift the burden of bureaucracy, empower communities, increase local financial control, diversify the supply of public services, create greater public transparency of government and, strengthen accountability to local people. [11, pp.1-7; 12, pp1-2]

Localism is said to be based on two uncontroversial facts 'that services are often provided in quantities and ways that do not reflect or involve the local communities' and that they are essentially sickness services without much emphasis on reducing illness and improving health and wellbeing.' [12, p.12] Subsidiarity and localism immediately bring to mind the concept of community engagement, a concept that all health systems pay at least 'lip service' to but to which many have substantial commitment to achieving. In fact, in the Australian context during the recent establishment of Primary Health Networks (PHNs) to provide a commissioning and development focus to primary healthcare (PHC), community engagement is a prescribed function to be achieved alongside clinical engagement. So the emphasis on'community engagement' is being elevated in importance and escalated in many health systems in its implementation and, it has enormous potential to contribute to healthcare. Are you adept, skilled and informed in all things that community engagement suggests and promises? Is it well entrenched in your health management lexicon?

The second assertion in the two uncontroversial facts mentioned above is that we deliver health services that are focussed on 'sickness' without the obvious need to both reduce illness and improve health and wellbeing. [12] This is not an unreasonable statement given demonstrated variability in utilisation and outcomes, the massive scale of the acute care sector and our want to provide both equity and access to all to services. However, that position ignores an important element of our health language that is reduced to, the socio-economic determinants of health (SEDOH) and that, in many developed nations states, there are obvious geographic areas, population groups and communities who have poor health status and outcomes demonstrated by assessment against those determinants. The data about 
both the status and the outcomes is unequivocal. These determinants are more obviously seen in addressing the health needs of developing countries but remain relatively invisible in developed countries approaches. Developing countries with the impact of the United Nations and the World Health Organisation have made significant progress through the application of Millennium Development Goals (MDGs) and, more recently in the progress to Sustainable Development Goals (SDGs). [13] Tejativaddhana and colleagues and Short and colleagues in this journal issue, both raise the critical importance of SDGs and, given they translate into measures of health outcomes, they are a critical factor mentioned by most authors in this journal issue. They also remind us that healthcare is just not about acute care and the process of care but includes both public health, preventative health and population health, societal factors and the outcomes of healthcare within our lexicon. Addressing SEDOH is not easy and progress may well be generational but it remains a central challenge and a significant contributor to the utilisation and costs of our sickness system and warrants greater prominence in our health management language and practice. It seems that moving the language of SEDOH, MDGs and SDG to a more central repository in the health management lexicon should be seen as a priority if health managers are to respond to the challenge of leadership in health reform.

A further consequence of the changing, shifting and transitioning of health reform and health management is the increasing alignment but not necessarily integration of the boundaries across traditional healthcare silos. Again, utilising the Australian example of establishing PHNs we see an alignment with the local health districts, focused on acute care services both in terms of geography and populations. Alignment of boundaries is public policy speak for collaboration at and across the boundaries, providing seamless care, integration where appropriate, clinical connectedness and clinical pathways and best practice. So in the health management language about roles this brings to the fore the concept of managers and leaders as boundary riders working at the edge of organisations and collaborating across boundaries. Equally, ideas and language can act as boundaries to our role and action. [14] The crossing of organisational boundaries suggests a shift away from hierarchies to the greater consideration of 'quasi markets' and network based approaches and an increased role of non-profit organisations. 'New Localism' has been described as 'a reaction against the target led and top down nature of...the NHS'. [15, p.39] This also brings into potential the value of the distributed networks of practice (DNoP) [16] in healthcare. Health professionals are familiar with community and/or networks of practice. DNoP provides the concept of collaboration to extend beyond single organisations, to those that can engage colleagues across organisations and geographic and national boundaries to improve care, provide education and undertake research in innovative contexts. These approaches can sit alongside existing organisational structures but do not respond effectively to prescriptive management. Gasson [17] and Wegner [18 ] talk in terms of 'brokering' as 'the transfer of an element from one community to another [17, p.3] So this brings our emphasis on the language into the brokering perspectives of 'translation, coordination and alignment of perspectives' into a network that furthers the alignment of interests' and to integrate knowledge. [17, p.3] Working across boundaries, in networks and brokering represents a challenge for traditional managers and organisations to live alongside and foster without damaging the potential of innovation by too much prescription. [19] These concepts suggest sensemaking as an important element of what managers do around 'linkages, structures, openness, capacity, reward, proximity and synergy'. [20, p.30]

\section{Health management workforce}

Short in this issue identifies the health workforce as both global and as a critical health management issue in the move towards achievement of sustainable health goals SDGs. In the national context, Martins and Isouard reported the first comprehensive study of health managers in Australia and their characteristics as at 2006 and 2011. [2125] That study determined the number and characteristics of health managers and those employed in aged care residential services, to inform policy and decision-making in various planning, workforce and strategic exercises to address future requirements. The voice of ongoing reform places the health management workforce under the strain of never ending change. It is common knowledge that health managers express widespread cynicism towards reform. The lexicon of mistrust and scepticism has built up over time when reform is talked up by governments and health departments yet rarely delivers the intended healthcare outcomes. In Australia the health workforce is seen as complex with overlapping clinical and other professional functions. [21,26] In particular, there is no universally recognised definition for a health manager, with no defined competency standards and qualifications recognised. This lack of established identity by health managers as a profession is seen as a likely contributor to issues arising 
in the attraction and retention of the health management workforce.

Although Martins and Isouard had identified that health managers have higher education qualifications than managers on average in all industries in Australia, [23] questions still remained as to whether their training and qualifications prepared them for the challenges posed by the constant systemic and other reform activities occurring. To investigate the latter, the authors developed an evidencebased model on competencies and skills for managers. [25] Their study undertook a strategic approach to identifying the competencies and skills required by health managers to handle systemic changes. The framework provided an evidence-based approach to identifying management competencies and skills based on real-world health management issues.

\section{The health management role}

Health professionals often undervalue the important role that health management plays within an organisation. Similarly, there is often little regard for the roles that health managers play in the introduction of reforms. Although it appears obvious that the possession of the required senior management skills seems vital to the success of the reforms, it hardly raises a mention in the language describing the proposals. The precise nature of the management role remains uncertain [27, p.123] but in healthcare it is described as unique, [28] while others have suggested that it is contested terrain, requiring critical examination. [29] Unlike the traditional approaches prescribed as 'capability frameworks', 'competencies' and 'skills' others describe the health management role as one that is seen as 'active participants, constructors, organisers and persuaders, emphasising the negotiation of meaning as being central to the role'. [2, p.643;7] Health reform 'challenges the dominant ways we think about management. [31, p.186] The health management role is 'situated in complex changing health systems' and is multi-dimensional. [2, p.644] Increasingly, as Weik suggested some time ago, management is increasingly focused on information gathering to seek certainty and to better construct the environment within a complex but adaptive system. [2]

This is in contrast to much of the current practice and curriculum where management continues to be practised in the normal rational and prescriptive fashion of traditional bureaucratic organisational structures. So this leads the authors to the hypothesis that health systems continue to manage in contexts and approaches that do not adequately enable successful implementation of health reform but facilitate the status quo. This suggests a need for further qualitative research to 'allow greater insight from their interpretation of their role'. [2] Mark 'argues for a more inclusive approach that provides the opportunity' [2] 'for the transfer of theory across sectors and cultures.' [32, p.863]

The language being presented to us from the research literature and from the authors in this issue suggest that existing hierarchical approaches dominated by 'managing upwards' will not facilitate health reform nor will it deliver capable health managers to lead that reform and mange in the new complex and adaptive systems that we are moving towards. In recognition of this the leading health management academics and researchers in Australia came together in 2008 to establish the SHAPE Declaration to 'promote public debate on the reform of the organisation and management of Health Services.' [33, p.11] At the time the Australasian College of Health Service Management also endorsed the Declaration.

The principles about health reform are encapsulated in the SHAPE Declaration, which states that:

1. Public policy should focus on improving health outcomes and not be prescriptive but provide frameworks of responsibility and cooperation at the program delivery level.

2. Reform should focus on the needs of communities and populations and structural arrangements should be determined in the light of that focus.

3. If government and public policy focus on principles and guidance, [34] then providers should be structured to meet the diversity of need and demonstrate good governance and management through proper engagement of structural interests.

4. Effective models of community engagement need to be incorporated into public policy and the governance of health services.

5. Health managers should be appropriately qualified, skilled and adept in managing complex health service organisations. [33, p. 11]

In moving forward, the Declaration suggests transitional reform, intersectoral arrangements and, the engagement of 'well qualified and competent management, engaged at all levels of reform and healthcare delivery'. [33, p.11] The centrality of health service management to health reform suggests:

1. Being trained and experienced to lead and manage in a 
range of differing health system and organisational arrangements.

2. Possessing a deep contextual understanding of health systems, public policy, professional cultures and politics.

3. Having competency in organisational sensemaking as negotiators of meaning, active participants, constructors, organisers and persuaders within health systems. [30]

4. Being drawn from a range of backgrounds including those with clinical and non-clinical experience and qualifications who can demonstrate broad contextual health knowledge that demonstrates more than one logic. [35]

5. Understanding how clinical work should be structured and managed and work actively with clinicians and others to deliver coherent, well-managed health services. [36]

Subsequently at the 1st International Conference on Health Service Delivery Management the first opportunity was provided for South East Asia and Pacific Regions to consider management and leadership contexts. Some 450 delegates from 17 countries and from 14 distinct health and education organisations met to consider revitalised primary healthcare systems and the requirement for well-trained professional health managers. The participants at that conference and those who organised it concluded the conference by declaring that:

1. Priority in resourcing and policy implementation should be given to developing leadership, management and governance as the means to strengthen health systems development.

2. Successful management of health services requires leadership and teamwork from managers who have positive personal and professional values and self perceptions and are empowered to engage with individuals and communities and to respond to the needs of the poor and marginalised groups.

3. Leadership for health systems, public health and PHC requires that managers have access to high quality education, training and experiential health context and knowledge that equips them to operate effectively in health systems.

4. A research culture is required that networks and engages in collaborative research to develop health management capacity and evidence as a basis for decisions, to guide policy development and that both challenges and aligns researchers and operational health systems professionals, citizens and communities. $[37$, p.29]

\section{Discussion}

There is no 'widespread agreement as to a definitive way to describe, let alone define the health manager's role and required capabilities'. [2; 38, p.71; 39] There is general consensus that it is unique given that it is exercised in complex adaptive systems that are politically dominated but most importantly are professionally dominated. [28] Health managers themselves agree with those descriptors but continue to describe the system as illness-based and a system of non-coordinated or not integrated entities. $[2,39]$ The multiplicity of professions contributing to success in the delivery and management of healthcare is important but is also recognised as contested territory between them in the management role and between health professionals and colleagues where they manage and also undertake a clinical role. $[40,41]$

The research described in this article suggests that health reform is starting to move beyond a focus on structure and restructure to giving licence or permission to implement reform that allows integration, connectedness and collaboration across boundaries. Those same boundaries that currently define healthcare are also blurring and widening in scope based on what civil society and community consider appropriate. Increasingly, the policies suggest that approaches involving commissioning and networking and the patient or care recipient as fund holder are seen as achievable. Many national policies and health systems are also suggesting engagement in reform with the civil society, social movements and approaches to address poor outcomes from the data on socio-economic determinants.

In these contexts, it is obvious that health systems and health management will not be advanced by continuing to do what has been done in the past and what is done currently. Therefore, it is important that health reform continues. It also means that health management needs to recognise the changing paradigm and begin to adapt the learning and approach needed to respond effectively. Management is and will remain variable and 'cannot be easily described or codified'. [38, p.72] We need to avoid circumstances where the role is described in prescriptive terms and is simplified. We should avoid the status quo, using a critical lens to challenge the dominant view of management. This may help us to make more sense of that variability and how roles are occupied and health management is practised in a more grounded way. [38]

This grounding in research of the health management role is necessary if we are to consider that role in informing 
and influencing health reform is often delivered in diffuse and contradictory terms. [38] Sensemaking is becoming central to the health management role in constituting self and the organisation. [42] This accentuates our proposition that it is most likely the language of health systems, health management and health reform that will inform our understanding of the new paradigm of delivering healthcare and the role we need to play in developing the capability of health managers and health leaders for that purpose.

Plesk, [38] Fraser and Greenhalgh [44] 'suggest that learning takes place in the zone of complexity and that building capability occurs' [28] when 'individuals engage in uncertain and unfamiliar contexts in a meaningful way'. [38, p.800] The authors and colleagues in the Society for Health Administration Programs in Education are collectively interested in advancing knowledge around the health management role and how we might go about that so that we might take up the challenge to demonstrate leadership in health reform. We welcome feedback, participation and additional contributions if you are also interested in joining us on our proposed journey.

\section{References}

1. Fournier V, Grey C. At the critical moment: conditions and prospects forcritical management studies. Human Relations. 2000; 53:7-32.

2. Briggs DS, Cruickshank $M$, Paliadelis P. Health managers and health reform. Journal of Management and Organisations. 2012;18(5): 641-658.

3. Legge $D$, Stanton $P$, Smyth A. Learning management (and managing your learning). In M.G.Harris \& Associates, editors. Managing health services: concepts and practices. 2nd ed. Sydney: Mosby Elsevier; 2006.

4. Degeling P, Carr A. Leadership for the systemization of healthcare: the unaddressed issues in healthcare reform. J Health Organ Manag. 2004;8(6):399-414.

5. Isouard G. National health reform success: it's all about leadership and management. Aust Q. 2010; 82(3):21-24.

6. Isouard G. Leading and managing the implementation process: the key to successful national health reform. Asia Pac J Health Manag. 2010;5(1):11-16.

7. Boxall A, Buckmaster L. Background note: options for reforming Australia's health system [accessed 3 Nov, 2016]. Parliament of Australia. Available from: http://www.aph.gov.au/About_Parliament/ Parliamentary_Departments/Parliamentary_Library/pubs/BN/0809/ HealthReform

8. World Health Report. 2000:231

9. Hartwich O. A global perspective on localism. Occasional Paper. Wellington: The New Zealand Initiative and Local Government New Zealand; 2013. Available from: http://nzinitiative.org.nz/site/ nzinitiative/files/publications/Global\%20Perspective\%20on\%20 Localism.pdf.

10. Raine J, Staite C. The world will be your oyster? Reflections on the Localism Act of 2011. Edgbaston: Institute of Local Government Studies, School of Government and Society, University of Birmingham; 2012.
11. HM Government. Decentralisation and the Localism Bill: an essential guide. London: Department for Communities and Local Government; 2010.

12. Greer SL. Four way bet: how devolution has led to four different models for the NHS. London: The Constitution Unit, The School of Public Policy, UCL; 2004. Available from: http://www.ucl.ac.uk/ constitution-unit/

13. WHO. From MDGs to SDGs: A new era for global public health 2016-2030. World Health Organisation; 2015. Available from: http://www.who.int/about/finances-accountability/funding/ financing-dialogue/MDGstoSDGs_Summary.pdf?ua=1

14. Mitchell R, Nicholas S. Knowledge creation through boundary spanning. Knowledge Management Research and Practice. 2006; 4:310-318.

15. Ferlie W. Systems and organisations. Public management 'reform' initiatives and the changing organisation of primary care. London Journal of Primary Care. 2010;3:76-80.

16. Briggs DS. So they want us to collaborate and innovate: how do we manage that? Asia Pac J Health Manag. 2013;8:1.

17. Gasson S. Boundary-spanning knowledgesharing in e-collaboration. Proceedings of the 38th Hawaii International Conference on Systems Sciences; [0-7695-2268-8].

18. Wenger E. Communities of practice - learning, meaning and identity. Cambridge UK: Cambridge University Press; 1998.

19. Ziam S, Landry R, Amara N. Knowledge brokers: a winning strategy for improving knowledge transfer and use in the field of health. International Review of Business Research Papers. 2009;5(4):491-505.

20. Estabrooks CA. Translating research into practice: Implications for organizations and administrators. Canadian Journal of Nursing Research. 2003;35(3):53-68.

21. Martins JM, Isouard G. Health Service Managers in Australia, Part 1: service, geographical and category distribution. A Pac J Health Manag. 2012a;7(2):16-28.

22. Martins JM, Isouard G. Health Service Managers in Australia, Part 2: age and sex characteristics. A Pac J Health Manag. 2012b; 7(2):29-42.

23. Martins JM, Isouard G. Health Service Managers in Australia, Part 3: field of study, level of education and income. A Pac J Health Manag. 2012c;7(2): 43-58.

24. Martins JM, Isouard G. Health Service Managers in Australia, Part 4: hours worked, marital status, country of birth and Indigenous status. A Pac J Health Manag. 2012c;7(2): 59-70.

25. Martins JM, Isouard G. Health Service Managers in Australia, progression and evolution. A Pac J Health Manag. 2014; 9(2):35-52.

26. Health Workforce Australia. National Health Workforce Innovation and Reform Strategic Framework for Action 2011-2015 [accessed 10 Nov 2016]. Adelaide: HWA; 2011. ISBN: 978-0-9871920-0-4, http://www.qrtn.com.au/images/pdf/Resources/hwa-wirstrategicframework-for-action-201110.pdf

27. Hewison A. Qualitative management research in the NHS: a classic case of counting to one? J Health Organ Manag. 2003; 17(2):122-137.

28. Mintzberg H. Towards healthier hospitals. Healthcare Manag Rev. 1997; 22(4):9-18.

29. Cunliffe A, Forray JM, Knights D. Considering management education: Insights from critical management studies. Journal of Management Education. 2002;26(5):489-495.

30. Elliott C, Reynolds M. Manager-educator relations from a critical perspective. Journal of Management Education. 2002; 26(5);512-526. 
31. Learmonth M. Guest Editorial; Tales of the unexpected? Stirring things up in healthcare management. J Health Organ Manag. 2005;19(3);181-188.

32. Mark A. Notes from a small Island: researching organisational behaviour in healthcare from a UK perspective. Journal of Organisational Behaviour. 2006;27:851-867.

33. Briggs DS. Shape Declaration on the Organisation and Management of Health Services: a call for informed public debate. 2008.

34. Kernick D. Vision in practice revisited: holding the NHS at the edge of chaos. Exeter: St Thomas Health Centre; 2003.

35. Ford JD, Ford LW. Logics of identity, contradiction, and attraction in change. Acad Management Rev. 1994;19(4):756-85.

36. Sorenson R, ledema R. Managing clinical processes in health services. Sydney: Elsevier; 2008.

37. Briggs DS, Tejativaddhana P, Kitreerawuttiwong N. Health declarations. Asia Pac J Health Manaag. 2010;5(1):25-30.

38. Briggs DS, Smyth A, Anderson JA. In search of capable health managers: what is distinctive about health management and why does it matter? Asia Pac J Health Manag. 2012; 7(7): 1-78.

39. Briggs DS. The lived experience of health service managers. [Dissertation]. Armidale: University of New England. 2008.

40. Briggs DS. Networks, democracy, innovation, pumpkins and pimples. Asia Pac J Health Manage. 2012;7(1):4-5.

41. Fitzgerald $A$, Teal G. Health reform, professional identity and subcultures: the changing interprofessional relations between doctors. Contemp Nurse. 2003;6(1-2):9-19.

42. Uhl-Bien M, Marion R, McKelvey B. Complexity leadership theory: shifting leadership from the industrial age to the knowledge era. Leadership Quarterly. 2007;8:4;298-318.

43. Plesk $P$, Greenhalgh $T$. The challenge of complexity in healthcare. BMJ. 2001;323;625-8.

44. Fraser SW, Greenhalg T. Coping with complexity: educating for capability. 2001. BMJ. 323:799-803. 